\title{
Análise da interface entre agregados reciclados de concreto e argamassas de concretos com cinza de casca de arroz e fíler basáltico por nanoindentação
}

\author{
Analysis of interfaces of recycled concrete aggregates and \\ concrete mortars with rice husk ash and basaltic filler by \\ nanoindentation
}

\section{Daniel Gustavo Brusius Wilbert Claudio de Souza Kazmierczak Marlova Piva Kulakowski}

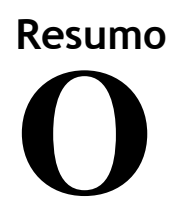
a partir de avaliações de propriedades mecânicas e microestruturais, e de melhorias na forma de mistura dos agregados. O presente trabalho analisa a viabilidade de utilização da técnica de nanoindentação para a avaliação da interface que se forma entre a pasta e o agregado reciclado em concretos com esse tipo de agregado. Foram produzidos corpos de prova que representam a região de interface em concretos em que os agregados reciclados foram adicionados à mistura no estado seco, método que vem sendo utilizado com o intuito de melhorar a zona de transição em função da absorção do excesso de água da pasta e de partículas de aglomerante pelos poros vazios do agregado reciclado. Os corpos de prova de referência foram comparados com outros em que foi realizada a adição de fíler basáltico e de cinza de casca de arroz. A técnica de nanoindentação possibilitou verificar que a utilização de agregado no estado seco gera zonas de transição de elevada qualidade e que a adição de cinza de casca de arroz aumenta a dureza da região de interface.

Palavras-chaves: Argamassa de concreto. Interface. Nanoindentação.

\section{Abstract}

Recycled concrete aggregates generally have inferior properties than natural aggregates, which means that their recycling possibilities are more limited. However, several studies have demonstrated the use potential of recycled concrete aggregates in the manufacture of concrete by determining their mechanical and microstructural properties, and improving the form of aggregate mixture. This study analyses the feasibility of using nanoindentation to evaluate the interface that is formed between the paste and the recycled aggregate in concretes with this type of aggregate. A new mortar layer was produced using different mix compositions. The admixture using RCA in dry state was used to improve the transition zone due to the absorption of excess water from the cement paste and the particle binders by the empty pores of the recycled aggregate. The reference samples were compared with samples where basalt fillers and rice husk ash had been added. The nanoindentation technique showed that the use of RCA in dry state generates high quality transition zones and that the addition of rice husk ash increases the hardness of the interface.

Keywords: Concrete mortar. Interface. Nanoindentation.

WILBERT, D. G. B.; KAZMIERCZAK, C. de S.; KULAKOWSKI, M. P. Análise da interface entre agregados reciclados de concreto e argamassas de concretos com cinza de casca de arroz e fíler basáltico por nanoindentação. Ambiente Construído, Porto Alegre, v. 17, n. 2, p. 253-268, abr./jun. 2017.

ISSN 1678-8621 Associação Nacional de Tecnologia do Ambiente Construído.

http://dx.doi.org/10.1590/s1678-86212017000200156 


\section{Introdução}

Na busca do desenvolvimento sustentável no setor da construção civil, tem-se como aliada a reciclagem de resíduos, que pode reduzir o consumo de matérias-primas não renováveis e energia, e minimizar a geração de poluição e o esgotamento de aterros (JOHN, 2000; VIEIRA, 2003). A reciclagem de materiais no setor de construção civil ganhou destaque em estudos no Brasil, como Zordan (1997), Lima, (1999), Pinto (1999), Ângulo (2000, 2005) e John (2000).

A reciclagem de resíduos da construção civil (RCC) em geral é feita na forma de agregados reciclados, que apresentam como características maior porosidade em relação aos agregados naturais e, por consequência, menor resistência e maior absorção de água. Essas propriedades resultam geralmente em novos concretos com piores propriedades mecânicas e menor durabilidade comparativamente aos confeccionados com agregados naturais.

O presente trabalho tem por objetivo analisar a viabilidade de utilização da técnica de nanoindentação para a avaliação da interface que se forma entre a pasta e o agregado reciclado de concreto (ARC) em concretos com esse agregado reciclado. Para isso foram utilizadas também uma adição inerte - fíler basáltico (FB) - e outra não inerte - cinza da casca de arroz (CCA) -, com o objetivo de verificar se essas adições causam alterações na região de interface e se podem ser identificadas pela técnica e também pela metodologia de análise proposta, visto que não existe uma metodologia consagrada para a análise de produtos cimentícios por nanoindentação.

\section{Revisão teórica}

Os ARC apresentam algumas diferenças em relação aos agregados naturais, principalmente quanto à existência de uma camada de argamassa aderida ao agregado natural, tornando-o mais poroso, com maior absorção, menor densidade e resistência (KATZ, 2003; TAM; GAO; TAM, 2005; ETXEBERRIA et al., 2007; KOU; POON, 2015). Para Padmini, Ramamurthy e Mathews (2009), a absorção é a principal propriedade que o difere de um agregado natural, influenciando as propriedades de concretos no estado fresco e endurecido. Werle, Kazmierczak e Kulakowski (2011) comprovaram que a absorção de um ARC está diretamente relacionada ao concreto que o originou. Os autores analisaram a absorção em ARC obtido de concretos de resistência de 18, 37 e $50 \mathrm{MPa}$, resultando em absorção de respectivamente $8,49 \%, 6,07 \%$ e $5,24 \%$. Outra característica de um ARC é a elevada absorção nos minutos iniciais, com estimativas de $90 \%$ nos primeiros $5 \mathrm{~min}$ (AGRELA et al., 2011; BUTTLER, 2003; TEGGUER, 2012). A argamassa aderida ao ARC também resulta em diminuição na massa específica ao se comparar com um agregado natural. Estudos, como os realizados por Ângulo et al. (2010) e Lovato (2007), afirmam que a massa específica é um parâmetro fundamental de qualidade de um agregado reciclado em geral; um ARC normalmente possui maior massa específica que agregados oriundos de RCC.

Por mais que as pesquisas demonstrem queda nas propriedades de concretos com ARC, fazendo com que autores como Evangelista e Brito (2007) e Topçu e Sengel (2004) recomendassem teores de somente $20 \%$ a $30 \%$ de substituição, a necessidade demanda que seja utilizada uma quantidade maior. Kou e Poon (2012) citam que a menor resistência e a maior porosidade do $\mathrm{ARC}$, somadas à quantidade utilizada, resultam em resistências inferiores aos concretos produzidos com esses agregados em comparação com o agregado natural. Além de resistências inferiores, o concreto com ARC é mais permeável que o concreto com agregados naturais, principalmente ao se utilizar agregado miúdo reciclado, fazendo com que a utilização de adições minerais seja extremamente benéfica em concretos com ARC (ZAHARIEVA et al., 2003).

\section{Zona de transição de concretos com ARC}

A zona de transição (ZT) possui uma estrutura diferente da região distante à superfície do agregado, apresentando grande quantidade de portlandita $\left(\mathrm{Ca}(\mathrm{OH})_{2}\right)$ e etringita, o que torna a região mais porosa. Esse efeito ocorre pela maior quantidade de água aderida à superfície do agregado, resultando em maior relação águacimento (a/c) na região, o que influencia diretamente as propriedades de durabilidade e mecânicas: exibe menor resistência e maior capacidade de deformação que a matriz e o agregado (PAULON; KIRCHHEIM, 2011; MEHTA; MONTEIRO, 2008; SICAT et al., 2014).

Bentz (2009) afirma que os principais fatores que influenciam a ZT são a relação a/c e o tipo de agregado, em função de sua superfície, porosidade e absorção. Nesse sentido, Ke et al. (2010) afirmam que, quando o agregado possui baixa capacidade de absorção, forma-se uma ZT mais porosa que a matriz. O tamanho e a forma do

254 Wilbert, D. G. B.; Kazmierczak, C. de S.; Kulakowski, M. P. 
agregado também influenciam a formação da ZT, pois maiores áreas superficiais resultam em maior quantidade de água, aumentando a porosidade, a formação de $\mathrm{Ca}(\mathrm{OH})_{2}$ e também a espessura da ZT. Já agregados mais rugosos proporcionam maior aderência, enquanto em agregados com superfícies mais lisas uma menor quantidade de pasta acaba ficando aderida ao agregado (ELSHARIEF; COHEN; OLEK, 2003; BASHER; BASHER; LONG, 2005; NEVILLE; BROOKS, 2013).

Concretos com agregados reciclados apresentam uma microestrutura mais complexa, pois o ARC possui duas zonas de transição, uma entre o ARC e a nova pasta de cimento, chamada de zona de transição nova, e outra no próprio ARC, entre seu agregado natural e a pasta antiga aderida, normalmente menos densa que a pasta nova, chamada de zona de transição antiga. Essa zona de transição antiga e a argamassa aderida correspondem à parte mais fraca do agregado reciclado, com uma grande quantidade de poros e fissuras (TAM; GAO; TAM, 2005; ETXEBERRIA; VÁZQUEZ; MARÍ, 2006, THOMAS et al., 2013). A zona de transição nova pode ter sua porosidade diminuída. A porosidade $\mathrm{e}$ a densidade da ZT nova dependem do estado de saturação do ARC no momento da mistura, porque esse estado de umidade influenciará a movimentação de água entre as duas argamassas. Utilizando agregados porosos e saturados, há um enfraquecimento da ZT, pela maior quantidade de água na região. Já com um agregado poroso e no estado seco, pode ocorrer um fortalecimento da ZT, pela absorção de água da mistura, o que proporciona a migração dos produtos de hidratação para dentro do ARC e consequentemente para a zona de transição (POON; SHUI; LAM, 2004).

O uso de adições também é benéfico para o fortalecimento da zona de transição. Trabalhos como os realizados por Xiao et al. (2013) e Kong et al. (2010) comprovaram as melhorias na ZT com o uso de adições, pela maior quantidade de C-S-H observada na região.

\section{Nanoindentação}

Blando (2005) afirma que a técnica de medida de dureza mais difundida e utilizada é a indentação, que analisa o comportamento elastoplástico da superfície de materiais, associando o controle computadorizado a sensores de deslocamento para a obtenção de resultados instantâneos do material. A técnica consiste na aplicação de uma carga por uma agulha (indentador ou penetrador) e é utilizada na medida de propriedades mecânicas, especialmente de materiais homogêneos, filmes finos e materiais em pequenos volumes. Esses testes dinâmicos são definidos como testes instrumentados de dureza (hardness instrumental tests - HIT) (JONES; GRASLEY, 2011).

A nanoindentação possui como princípio uma técnica simples em que o penetrador, de geometria e propriedades conhecidas, é pressionado em um material até que a carga ou profundidade previamente definida seja alcançada. A partir desse momento, o indentador é removido da amostra. Durante o processo o material se deforma, refletindo as propriedades mecânicas (CONSTANTINIDES; ULM, 2004, 2007). O teste inicia-se com o penetrador entrando em contato com o material, no valor de carga mínimo, e a partir do contato a carga vai sofrendo incrementos, dando início ao ciclo de carregamento. Esse ciclo é finalizado com o alcance da carga máxima, que tem duração preestabelecida, período chamado de tempo de retenção na carga máxima, iniciando-se então o ciclo de descarregamento. No ciclo de descarregamento o indentador sofre reduções de carga até alcançar o valor de carga mínima, finalizando o teste com a retirada completa do indentador da amostra (BLANDO, 2005).

A penetração do indentador dentro do material no ciclo de carregamento provoca deformações elásticas e plásticas, estimando-se assim, pela profundidade de penetração e de acordo com o penetrador utilizado de propriedades conhecidas, seu valor de dureza. Na fase de descarga (remoção do indentador) somente a porção elástica do material é restabelecida, sendo dessa maneira possível conhecer o módulo de elasticidade do material, uma vez que durante o ciclo de descarga a deformação do material está diretamente ligada à recuperação elástica do material (BLANDO, 2005; ZHU et al., 2007).

A técnica de nanoindentação, que foi originalmente desenvolvida para materiais homogêneos, metálicos e cerâmicos, ao contrário do concreto, extremamente heterogêneo, vem nos últimos anos sendo utilizada para a análise de materiais cimentícios, como o clínquer, compostos do cimento hidratado, argamassas e concretos. Porém, em função da heterogeneidade de materiais à base de cimento, para uma análise estatística confiável, se fazem necessárias centenas de indentações em uma única amostra, e uma complexa validação por análise estatística (JENNINGS et al., 2007; ULM et al., 2010).

Entre os trabalhos já realizados destacam-se aqueles que vêm medindo as propriedades dos compostos do cimento hidratado, como os de Constantinides e Ulm (2004, 2007), Venkovic, Sorelli e Martirena (2014) e Silva, Nemecek e 
Stemberk (2014), os quais demonstram principalmente a existência de dois compostos de $\mathrm{C}-\mathrm{S}-\mathrm{H}$, que se assemelham na composição, mas que diferem estruturalmente entre si, sendo um de alta densidade e outro de baixa densidade. Esses trabalhos ainda demonstram que as propriedades elásticas do C-S-H são intrínsecas ao composto. Para Jennings et al. (2007), os valores de módulo de elasticidade dos C-S-H de pasta de cimento de baixa densidade ficaram na ordem de $18 \mathrm{GPa}$, enquanto o de alta densidade ficou na ordem de $31 \mathrm{GPa}$. A Tabela 1 apresenta o resultado de diferentes trabalhos que analisaram os produtos de hidratação por nanoindentação.

\section{Programa experimental}

Foi utilizado cimento CP II-F-32, pois possui menor quantidade de adições que cimentos do tipo CP III e CP IV, e menor superfície específica que um CP V. A massa específica do cimento adotado foi de 2,91 $\mathrm{g} / \mathrm{cm}^{3}$. O fíler basáltico (FB) utilizado foi obtido por britador do tipo VSI, em pedreira localizada em Campo Bom, RS, e submetido a peneiramento para garantir a utilização de material passante na peneira $0,075 \mathrm{~mm}$. Apresentou massa específica de $2,63 \mathrm{~g} / \mathrm{cm}^{3}$. A cinza de casca de arroz (CCA), utilizada também por Fedumenti (2013) e por Erhart (2014), é oriunda de Alegrete, RS, e obtida a partir da queima da casca em forno de leito fluidizado. A CCA possui massa específica de 2,07 $\mathrm{g} / \mathrm{cm}^{3}$ e classifica-se, conforme a NBR 12653 (ABNT, 2014), como uma pozolana de classe $\mathrm{E}$, com teor elevado de sílica, cuja soma dos compostos de $\mathrm{SiO}_{2}, \mathrm{Al}_{2} \mathrm{O}_{3}$ e $\mathrm{Fe}_{2} \mathrm{O}_{3}$ representa um total de $95,23 \%$.

A caracterização mineralógica das adições foi realizada por difração de raios $\mathrm{X}$, visualizada na Figura 1. O FB apresentou grande quantidade de picos cristalinos, especialmente de labradorites, e a CCA, uma pequena quantidade de picos de cristobalita e quartzo.

O resultado da distribuição granulométrica do cimento e adições está exposto na Figura 2.

O agregado miúdo natural (AMN) utilizado foi uma areia quartzosa de leito de rio, proveniente do Rio Jacuí, na região de Porto Alegre, RS. Foi utilizada somente a fração passante na peneira de malha $4,80 \mathrm{~mm}$ e retida por lavagem na peneira $0,075 \mathrm{~mm}$, que resultou, após lavagem, num teor de material passante na peneira $75 \mu \mathrm{m}$, conforme a NBR NM 46 (ABNT, 2003), de 0,16\%. A Tabela 2 apresenta as propriedades da areia, e a Figura 3, sua distribuição granulométrica.

Tabela 1 - Módulo de elasticidade em materiais cimentícios (GPa), obtido por nanoindentação

\begin{tabular}{l|c|c|c}
\hline & Constantinides e Ulm (2004) & Sorelli et al. $\mathbf{( 2 0 0 8 )}$ & Hu e Li (2015) \\
\hline C-S-H de baixa densidade & $21,7 \pm 2,2$ & $19,7 \pm 2,5$ & 24,2 \\
C-S-H de alta densidade & $29,4 \pm 2,4$ & $34,2 \pm 5,0$ & 30,3 \\
CH & $38 \pm 5$ & - & 36,4 \\
Microporo & - & $7,0 \pm 4,0$ & 0,0 \\
Macroporo & - & - & 0,0 \\
Pasta de cimento & - & - & - \\
Areia & - & $76,3 \pm 15,1$ & - \\
Cimento anidro & - & $141,1 \pm 34,8$ & 90,3 \\
\hline
\end{tabular}

Figura 1 - Difração de raios X FB e CCA

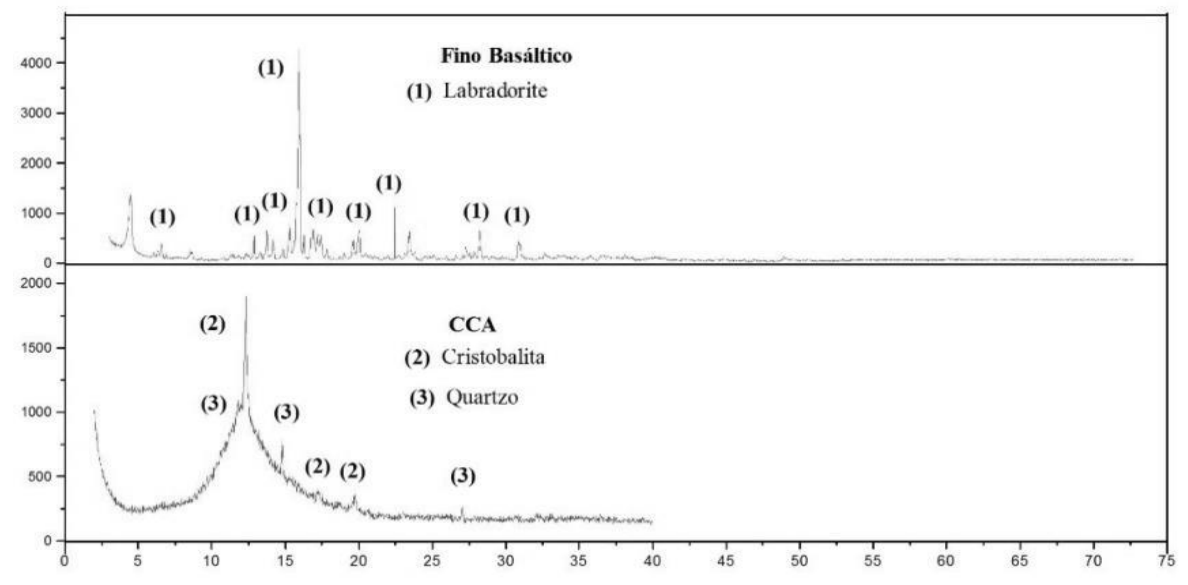

256 Wilbert, D. G. B.; Kazmierczak, C. de S.; Kulakowski, M. P. 
Figura 2 - Distribuição granulométrica dos materiais obtida por granulometria a laser

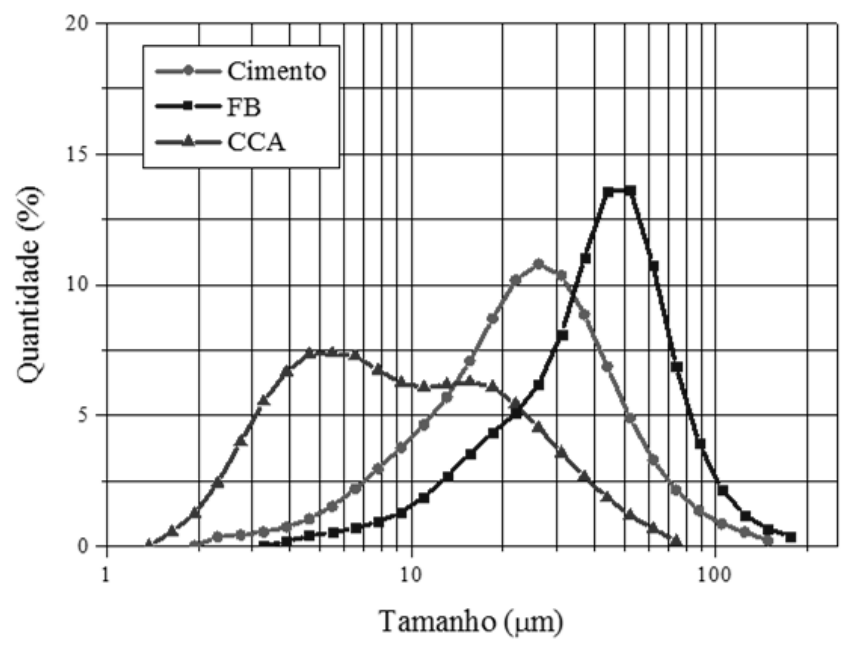

Tabela 2 - Propriedades do AMN

\begin{tabular}{l|c|c}
\hline \multicolumn{1}{c|}{ Propriedade } & Resultado & Metodologia \\
\hline Massa unitária $\left(\mathrm{g} / \mathrm{cm}^{3}\right)$ & 1,50 & NBR NM 45 (ABNT, 2006) \\
Massa específica $\left(\mathrm{g} / \mathrm{cm}^{3}\right)$ & 2,60 & NBR NM 52 (ABNT, 2003) \\
Dimensão máxima característica $(\mathrm{mm})$ & 2,40 & NBR NM 248 (ABNT, 2003) \\
Módulo de finura & 2,08 & NBR NM 248 (ABNT, 2003) \\
\hline
\end{tabular}

Figura 3 - Distribuição granulométrica do AMN

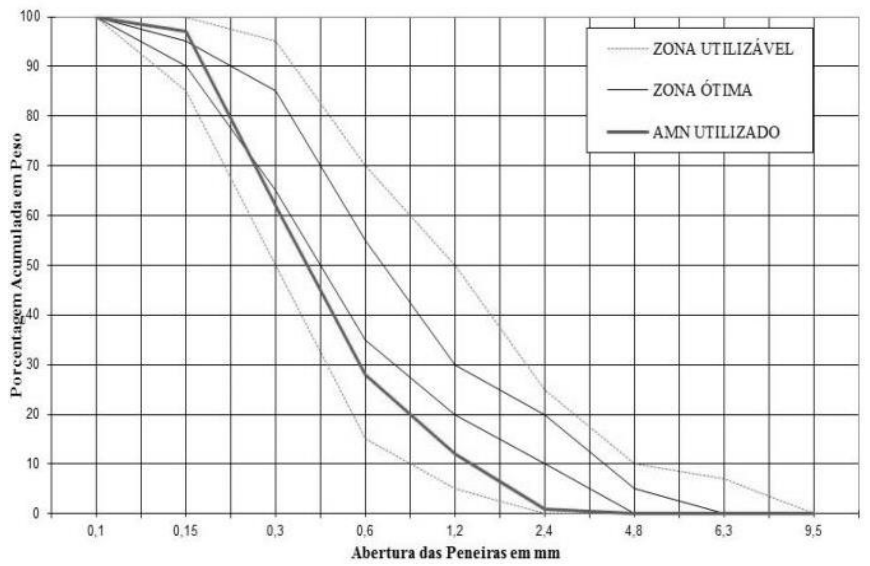

Exclusivamente para a análise da interface pastaagregado, foi utilizado um basalto proveniente de Nova Prata, RS, com massa específica de 2,66 $\mathrm{g} / \mathrm{cm}^{3}$, segundo a NBR NM 53 (ABNT, 2002).

A água utilizada foi proveniente da rede pública de São Leopoldo, RS.

Utilizou-se o traço de concreto 1: 2,815:3,25:a/c $=0,62$, descrito na pesquisa de Padovan (2013). No presente estudo o agregado graúdo foi retirado, sendo utilizadas apenas as argamassas. A quantidade de materiais manteve-se fixa, assim como a relação a/c, variando-se apenas o tipo e o teor de adição, utilizada em adição ao cimento, em massa com compensação de volume. A Tabela 3 apresenta os consumos de materiais para os diferentes traços.

A mistura dos materiais foi realizada em argamassadeira de eixo vertical, seguindo o procedimento especificado na NBR 7215 (ABNT, 1996), com as adições de agregados reciclados sendo adicionadas ao cimento. Após a mistura, foram moldados corpos de prova cilíndricos de dimensão $5 \times 10 \mathrm{~cm}$, que permanecerem nos moldes por 24 h, até ser desmoldados e levados à câmara úmida, com temperatura e umidade de respectivamente $23 \pm 2{ }^{\circ} \mathrm{C}$ e $97,5 \pm 2,5 \%$, onde permaneciam até a idade de 28 dias, para então ser caracterizados. 
Tabela 3 - Traços utilizados

\begin{tabular}{c|c|c|c|c|c}
\hline Identificação & Cimento & Agregado miúdo & Água/Cimento & FB (\%) & CCA (\%) \\
\hline Ref & 1 & 2,815 & 0,62 & - & - \\
$5 \%$ FB & 1 & 2,815 & 0,62 & 5 & - \\
$10 \%$ FB & 1 & 2,815 & 0,62 & 10 & - \\
$5 \%$ CCA & 1 & 2,815 & 0,62 & - & 5 \\
$10 \%$ CCA & 1 & 2,815 & 0,62 & - & 10 \\
\hline
\end{tabular}

Nota: Todas as argamassas apresentaram consistência por espalhamento de $360 \pm 10 \mathrm{~mm}$.

As propriedades das argamassas avaliadas aos 28 dias foram:

(a) massa específica: medida na condição saturada, antes da realização dos ensaios;

(b) módulo de elasticidade dinâmico: medido com aparelho "Pundit" (Portable Ultrasonic Nondestructive Digital IndicatorTester), PunditLab, da empresa Proceq, e com base na NBR 8802 (ABNT, 2013);

(c) resistência à compressão axial: realizada com base na NBR 5739 (ABNT, 2005) e na NBR 7215 (ABNT, 1996), utilizando uma velocidade de carregamento de $0,30 \mathrm{MPa} / \mathrm{s}$, em prensa classe I, da marca Controls, com capacidade de $2.000 \mathrm{kN}$; e

(d) porosimetria por intrusão de mercúrio (PIM): realizada em equipamento Quanta Chrome Pore Master, com pressão de intrusão de mercúrio de 0 a $0,34 \mathrm{MPa}$ na baixa pressão e de 0,34 a 227,37 MPa na alta pressão, com um ângulo de contato de $130^{\circ}$, na idade de 28 dias.

Com exceção do ensaio de PIM, todos os demais foram realizados em três corpos de prova, adotando-se a média como resultado.

\section{Metodologia de análise da interface entre argamassas por nanoindentação}

Para o estudo da interface entre a argamassa e o agregado reciclado, foram moldados corpos de prova simulando um concreto com ARC. Os métodos de produção dos corpos de prova se basearam nos trabalhos realizados por Poon, Shui e Lam (2004), Kong et al. (2010) e Xiao et al. (2013), que analisaram a zona de transição que ocorre em concretos com ARC. O objetivo pelo qual foram adotados esses tipos de corpos de prova foi a obtenção de uma interface padronizada que fosse mais bem representada e facilmente identificada em todas as amostras.

Inicialmente foram moldados corpos de prova para representar um ARC. Nessa etapa se utilizou um filete de basalto de dimensões $1 \times 2 \times 16 \mathrm{~cm}$, que foi disposto na lateral de uma fôrma prismática de dimensão 4x4x16 cm, para então ser aplicada a camada de argamassa no basalto. O traço dessa argamassa foi mantido fixo em todas as amostras, sendo utilizado o traço referência (sem adição). Após 21 dias de cura, esses corpos de prova tiveram parte de sua argamassa serrada, para garantir uma espessura de argamassa no basalto de $5 \pm 1 \mathrm{~mm}$. A Figura 4 demonstra a amostra antes e após a etapa de corte. Após o corte, os exemplares tinham sua face limpa em água corrente e pincel de cerdas macias por um período de 2 min, para então ser curados por mais 7 dias, totalizando 28 dias, até ter sua hidratação paralisada.

A paralisação da hidratação ocorria submergindo os exemplares em álcool isopropílico por $30 \mathrm{~min}$, e posteriormente em estufa de $60^{\circ} \mathrm{C}$ por $24 \mathrm{~h}$, pois um período ou temperatura maior em estufa poderia resultar no desplacamento da camada de argamassa. Após o período de 24 h, os exemplares eram levados para outra estufa, com temperatura de $40{ }^{\circ} \mathrm{C}$, onde permaneciam até a aplicação da nova camada de argamassa. Para a aplicação da nova camada de argamassa foram utilizados os cinco traços produzidos nas propriedades macroestruturais, conforme a Tabela 3 . O uso das adições e dos diferentes teores teve por objetivo verificar se pela técnica da nanoindentação e pelos métodos de análise propostos é possível identificar alterações na região de interface entre duas argamassas de concreto. A aplicação da nova camada de argamassa ocorreu da mesma maneira que na produção do ARC, com esse disposto lateralmente em fôrma prismática, porém no tamanho $4 \times 8 \times 16 \mathrm{~cm}$, com o objetivo de se ter uma camada maior de argamassa nova em relação à camada de argamassa velha, e mantendo-se a altura em $2 \mathrm{~cm}$. O método de cura também se manteve fixo, porém o período de cura adotado foi de 63 dias. Nesse período estima-se que a reação pozolânica já tenha ocorrido quase que em sua totalidade, podendo-se, dessa maneira, analisar a real influência do uso da CCA. Após o período de cura os exemplares tinham sua hidratação paralisada da mesma maneira que os ARC. A Figura 5 mostra o corpo de prova após a desmoldagem. 
Figura 4 - ARC antes e após o corte
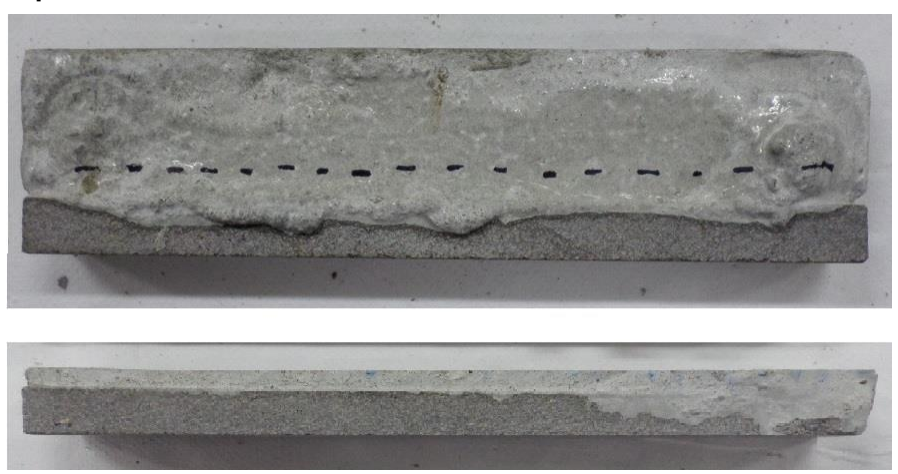

Figura 5 - Corpo de prova de ARC com argamassa nova

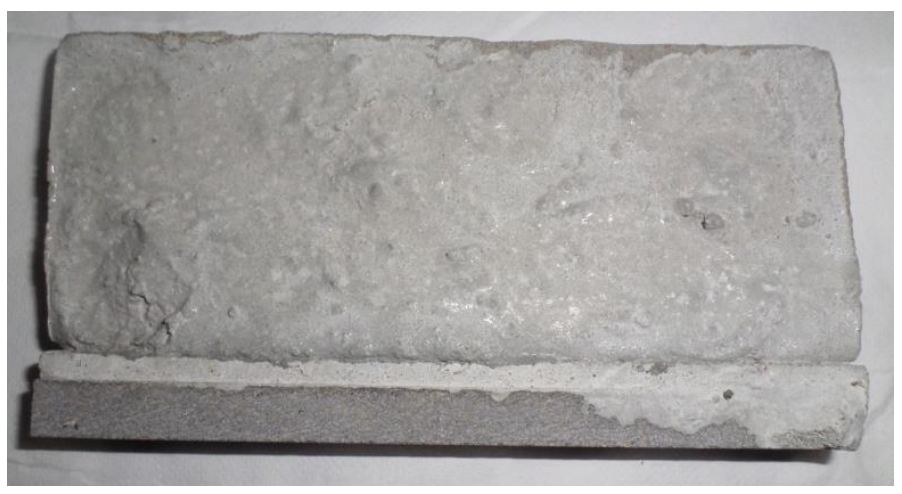

Para a realização das medidas de nanoindentação, a superfície a ser analisada precisa atender a alguns requisitos básicos, principalmente quanto a sua planicidade e polimento, minimizando, dessa forma, a variabilidade nos resultados que ocorrem pela rugosidade da superfície. O primeiro passo foi a obtenção da amostra, de dimensão de cerca de 10x10x10 mm, por corte em serra de precisão com lâmina diamantada e álcool isopropílico como refrigerante. Devido ao fato de a amostra ser extremamente sensível, a etapa de corte é realizada com extrema acuidade, evitando que ocorra o desplacamento entre as diferentes camadas. Após a obtenção da amostra, ela é enxaguada em recipiente com álcool isopropílico e levada à estufa de $40{ }^{\circ} \mathrm{C}$ para secagem. Com a amostra seca, ocorre o processo de embutimento com resina epóxi EMBed 812, realizado a quente, e secagem por $24 \mathrm{~h}$ em estufa de temperatura de $60^{\circ} \mathrm{C}$. Após, é feito o lixamento em politriz, utilizando-se lixas de carbeto de silício nas granas de 320, 400, 600, 800 e 1.200 . Após o lixamento a amostra é polida com pasta de alumina nas granas de $1 \mu \mathrm{m}$ e 0,3 $\mu \mathrm{m}$. O processo é constantemente conferido em microscópio óptico, para garantir uma superfície plana, lisa e sem riscos oriundos do lixamento.
A identificação da região de interface foi feita com o auxílio de um microscópio óptico Carl Zeiss Axiovision M2m, em ampliações de 25, 50 e 100 vezes. Em função da quantidade de amostras foi definido o número de 25 medidas de nanoindentação por amostra, viabilizando a realização do ensaio em um número maior de amostras. As medidas foram divididas em três linhas perpendiculares à interface, com sete medidas em cada, além de mais quatro medidas ao longo da interface, realizando-se, assim, uma maior quantidade de pontos na interface. As distâncias entre os pontos mantiveram-se fixas, variando-se apenas a distância entre as linhas. Dessa maneira há a possibilidade de evitar que uma linha de medição ocorra sobre grande quantidade de agregados. A Figura 6 detalha a disposição das medidas realizadas.

As medidas de nanoindentação foram realizadas no Parque Científico e Tecnológico da PUCRS (TecnoPUCRS), no Centro de Física, no Grupo de Estudo de Propriedades de Superfícies e Interfaces (Gepsi), em equipamento FischerScope H100VPXY. Para a execução do ensaio foram utilizadas as seguintes configurações: penetrador: Berkovich; carga: $50 \mathrm{mN}$; tempo: $40 \mathrm{~s}$; e tempo de retenção na carga máxima: $5 \mathrm{~s}$. 
Figura 6 - Localização dos pontos a serem medidos

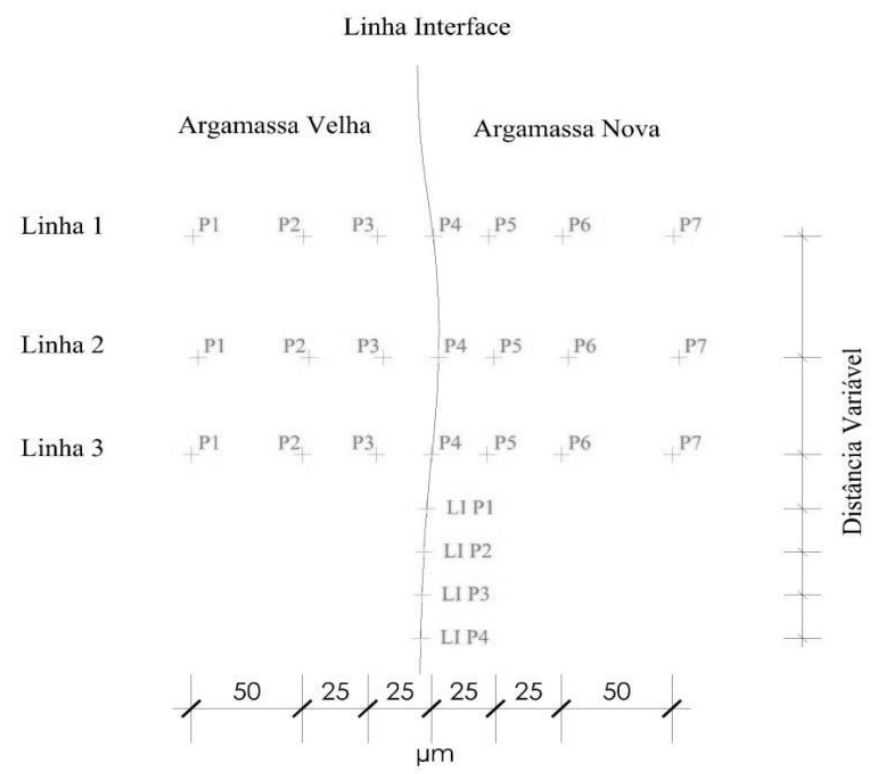

\section{Método de análise dos resultados}

Como não há método de análise da técnica consagrado, foram desenvolvidos três métodos de análise com base na quantidade de medidas realizadas, para poder identificar se o uso das adições resultou em alteração na região de interface.

\section{Método 1}

Esse método tem por objetivo identificar alterações apenas na região da argamassa nova através da média aritmética do módulo de elasticidade dinâmico e considera:

(a) todos os valores medidos; $\mathrm{e}$

(b) somente os valores situados abaixo de $45 \mathrm{GPa}$.

As Tabelas 1 e 4 (obtidas através de medições por nanoindentação somente no agregado miúdo natural - AMN) demonstram que valores de módulo acima de $45 \mathrm{GPa}$ são resultados característicos do AMN e de partículas de cimento não hidratado.

\section{Método 2}

Este método tem por objetivo analisar a interface, em diferentes extensões de leitura, também pela média aritmética dos valores de módulo de elasticidade dinâmico e considera os seguintes parâmetros:

(a) exclusão dos pontos com valores $\geq 45 \mathrm{GPa}$, que representam agregados e partículas de cimento não hidratado; e (b) adoção de quatro áreas de abrangência de leituras de nanoindentação, com extensão variável.

Como a região de interface não é uma reta (representada na Figura 6), procurou-se avaliar se há diferenças entre a região de análise e a área vizinha comparando-se os valores de módulo de elasticidade encontrados por indentações em uma área com $75 \mu \mathrm{m}$ de largura (onde se identificou por microscopia óptica a interface entre a argamassa velha e a nova - é a extensão "a" citada a seguir) e os valores de módulo obtidos em áreas com maior dimensão, cujas extremidades em princípio estão fora da ZT visível por microscopia óptica e cujo módulo, pressupõe-se, seja maior.

Foram avaliadas as seguintes extensões:

(a) $75 \mu \mathrm{m}: 25 \mu \mathrm{m}$ além da linha interface para a argamassa velha e $50 \mu \mathrm{m}$ para a argamassa nova;

(b) $100 \mu \mathrm{m}: 25 \mu \mathrm{m}$ além da linha interface para a argamassa velha e $75 \mu \mathrm{m}$ para a argamassa nova;

(c) $150 \mu \mathrm{m}: 50 \mu \mathrm{m}$ além da linha interface para a argamassa velha e $100 \mu \mathrm{m}$ para a argamassa nova; $\mathrm{e}$

(d) $200 \mu \mathrm{m}: 100 \mu \mathrm{m}$ além da linha interface para a argamassa velha e $100 \mu \mathrm{m}$ para a argamassa nova.

Autores como Diamond e Huang (2001), Wang et al. (2009) e Sidorova et al. (2014) estimam a espessura da ZT entre $50 \mu \mathrm{m}$ e $100 \mu \mathrm{m}$, e encontraram um módulo de elasticidade nessa região menor que o observado na pasta. 
Tabela 4 - Módulo de elasticidade medido nos grãos do AMN utilizado na pesquisa

\begin{tabular}{l|c}
\hline \multicolumn{1}{c|}{ Medida } & Resultado \\
\hline Média $(\mathrm{GPa})$ & 72,06 \\
Desvio padrão $(\mathrm{GPa})$ & 18,63 \\
Valor máximo $(\mathrm{GPa})$ & 96,65 \\
Valor mínimo $(\mathrm{GPa})$ & 47,63 \\
\hline
\end{tabular}

Através desse método estima-se identificar se o módulo de elasticidade da região de interface entre o agregado reciclado e a argamassa nova é menor, o que caracteriza uma típica ZT, e se as adições foram capazes de melhorar essa região.

\section{Método 3}

Conforme exposto na Tabela 1, a técnica da nanoindentação demonstra que há grande heterogeneidade entre os compostos cimentícios, a partir da alta variabilidade dos resultados. Dessa maneira, uma análise exclusivamente pela média aritmética pode negligenciar a real situação na interface, pois a média entre um valor de módulo de elasticidade alto, que pode representar $\mathrm{Ca}(\mathrm{OH})_{2}$, e um valor baixo, característico de poros e vazios, resulta em um valor de módulo de elasticidade intermediário, típico de $\mathrm{C}-\mathrm{S}-\mathrm{H}$, não tendo relação com os demais. Portanto, no método 3 se utilizaram as mesmas extensões de leitura (75, 100,150 e $200 \mu \mathrm{m}$ ) utilizadas no método 2 , porém individualizando as seguintes faixas de valores:

(a) acima de $45 \mathrm{GPa}$, considerado como agregados e cimento não hidratado;

(b) entre 35 e $45 \mathrm{GPa}$, considerado como $\mathrm{Ca}(\mathrm{OH})_{2}$;

(c) entre 15 e $35 \mathrm{GPa}$, considerado como C-S-H; $\mathrm{e}$

(d) menor que $15 \mathrm{GPa}$, considerado como poros e vazios.

Para a análise foram levados em consideração somente os valores considerados como C-S-H ou os considerados como poros e vazios.

\section{Resultados e discussão}

Os resultados dos ensaios de caracterização macroestrutural das argamassas produzidas estão apresentados na Figura 7.

A adição de fíler de basalto exerceu pouca influência nas propriedades mecânicas da argamassa, enquanto a adição de CCA melhorou substancialmente tais propriedades. A adição de CCA provoca densificação da argamassa, elevando a massa específica, a resistência à compressão e a resistência à tração das argamassas, em função do efeito pozolânico e de sua granulometria, mais fina que a do cimento (Figura 2). As maiores resistências encontradas para cada tipo de adição ocorreram nos teores de adição de $10 \%$, com o FB proporcionando uma elevação em relação à referência de $6 \%$, e a $\mathrm{CCA}$ de $61 \%$. O melhor desempenho da CCA contra o FB também ocorreu na resistência à tração, em que os dois teores de adição de FB proporcionaram elevação de $23 \%$, enquanto as argamassas com CCA aumentaram sua resistência em $45 \%$ e $55 \%$, em função do teor de adição.

A quantidade de poros determinada pela quantidade de mercúrio intrudido por porosimetria (Figura 8) demonstrou que a porosidade da argamassa se manteve nas misturas com adição de $5 \%$ de FB e aumentando no teor de $10 \%$. Contrariamente, as argamassas com adição de CCA diminuíram sua porosidade, notoriamente para o teor de $10 \%$ em relação às argamassas de referência. Esse comportamento é esperado, em função dos novos produtos de hidratação decorrentes da reação pozolânica.

A porosimetria justifica em nível microestrutural as propriedades macroestruturais das argamassas. Entretanto, essa técnica não permite a avaliação das propriedades das regiões de interface pastaagregado. A utilização da nanoindentação buscou preencher essa lacuna a partir da avaliação dos módulos de elasticidade nas regiões de interface e vizinhanças, apresentados na sequência.

\section{Avaliação de módulo de elasticidade por nanoindentação segundo o método 1}

Os valores médios de módulo de elasticidade determinados por nanoindentação na região correspondente à argamassa nova (Figura 9) aparentam um acréscimo de módulo em função da adição de $10 \%$ de FB e de qualquer teor de CCA. Entretanto, a se excluírem os valores superiores a 45GPa, o efeito da adição diminui consideravelmente, o que, em conjunto com as propriedades mecânicas, indica que o método não explica adequadamente os fenômenos decorrentes do uso das adições. A adição de CCA nos teores de $5 \%$ e $10 \%$ resultou em elevação no módulo de 
elasticidade em comparação com a referência de respectivamente $42 \%$ e $51 \%$.

\section{Avaliação de módulo de elasticidade por nanoindentação segundo o método 2}

As médias aritméticas dos valores de módulo de elasticidade obtidos pelas indentações realizadas, considerando-se apenas os valores abaixo de 45

Figura 7 - Caracterização macroestrutural

\section{Massa Específica}

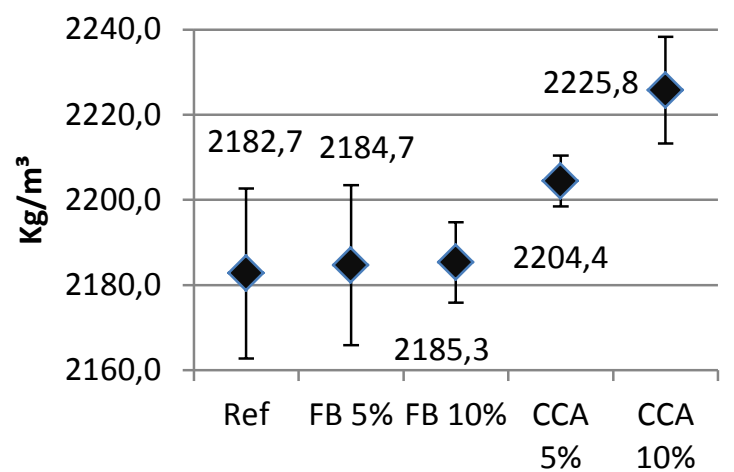

\section{Resistência à Compressão}

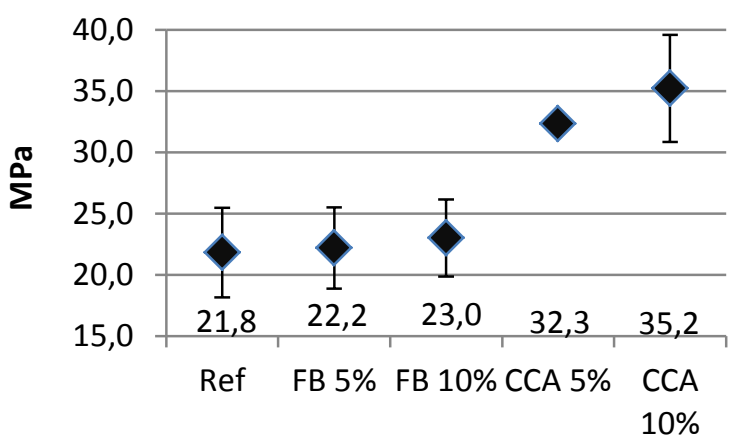

GPa, nas diferentes extensões de análise estão expostas na Figura 10.

Ao se analisarem os resultados em função do traço, observa-se que, independentemente do tamanho da região de análise, as argamassas com CCA resultaram em interfaces mais rígidas, ao contrário das argamassas com FB, que apresentaram resultados similares aos encontrados na referência.

\section{Módulo de Elasticidade Dinâmico}

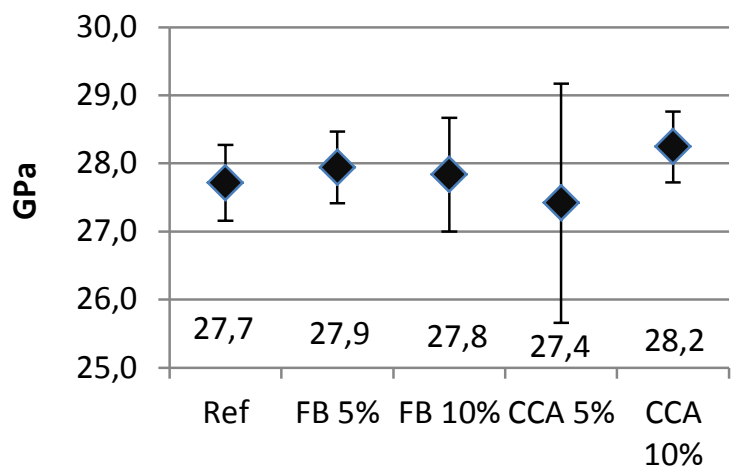

Resistência à Tração

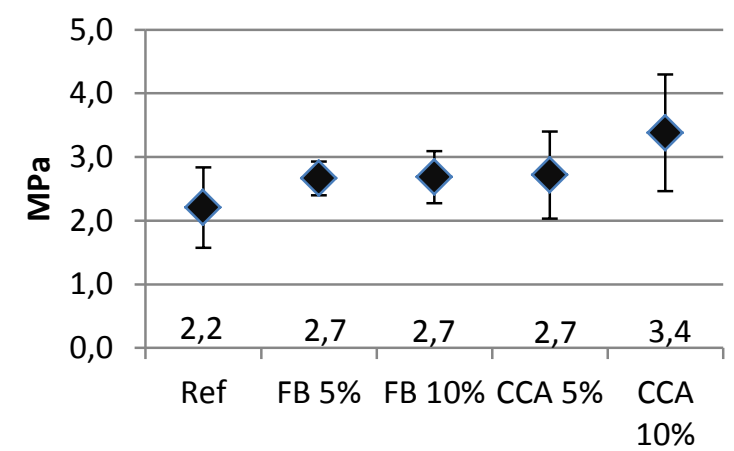

Figura 8 - Porosidade das argamassas determinada por PIM

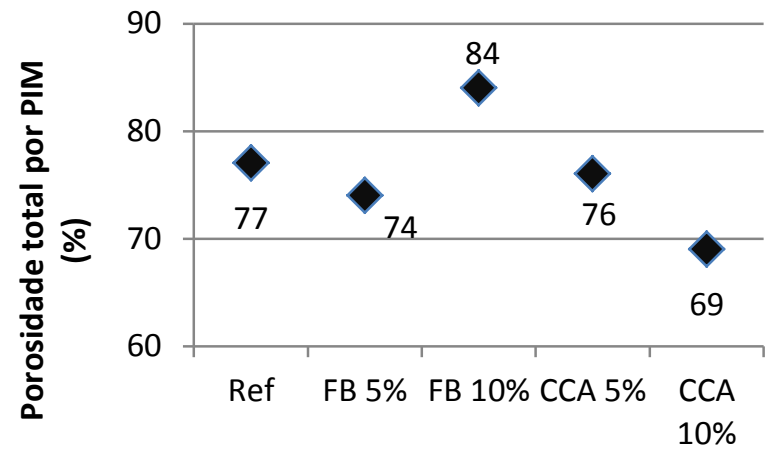


Figura 9 - Valores médios de módulo de elasticidade - método 1

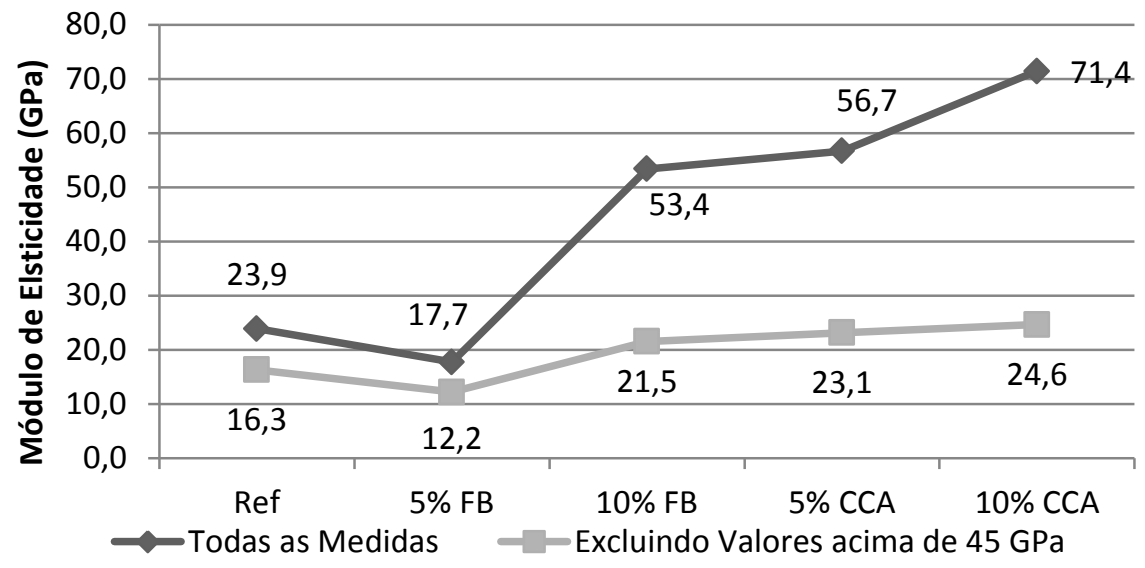

Figura 10 - Valores médios de módulo de elasticidade - método 2

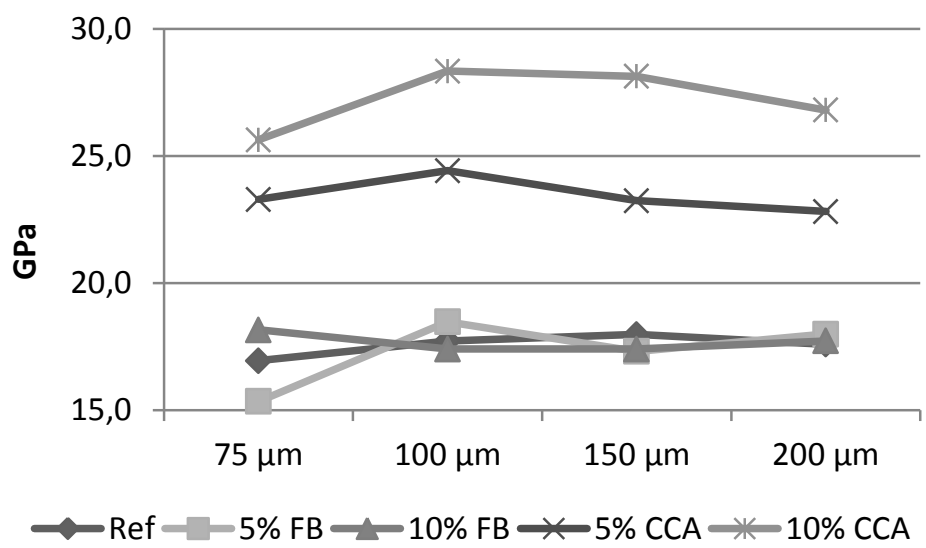

Avaliando-se cada traço individualmente, constatase que não há consideráveis alterações de módulo de elasticidade em função do aumento da região de análise, o que indica que a região de interface de todas as argamassas não apresentou diferenças com relação à matriz. Como em concretos plásticos com agregados convencionais é usual se identificar uma região de menor módulo de elasticidade, típica de zona de transição, pode-se deduzir que o processo de confecção dos exemplares analisados, em que os agregados reciclados são inseridos na mistura no estado seco, minimizou os efeitos de aumento da porosidade da zona de transição, praticamente igualando a dureza entre as argamassas e sua região de interface.

\section{Avaliação de módulo de elasticidade por nanoindentação segundo o método 3}

A análise pelo método 3 também ocorreu comparando-se diversas extensões ao longo do eixo que define a interface entre a argamassa nova e a antiga. Entretanto, em cada extensão analisada, procurou-se identificar faixas de valores típicas de produtos cimentícios.

Os valores situados entre $15 \mathrm{GPa}$ e $35 \mathrm{GPa}$ (típicos de C-S-H) estão expostos na Figura 11, onde estão plotadas as médias aritméticas (esquerda) e o percentual de medidas que se situaram nessa faixa (direita) em relação ao total de valores de módulo de elasticidade entre zero e $45 \mathrm{GPa}$.

Verifica-se que a adição de FB diminui a formação de compostos de C-S-H na região da interface em comparação com a argamassa de referência. Esse comportamento é observado tanto na média do módulo de elasticidade desses compostos quanto no percentual, embora não corresponda ao esperado em função dos resultados das análises macroestruturais, em que o comportamento mecânico foi similar. Para as argamassas com adição de CCA, apenas o teor de $10 \%$ de adição resultou em aumento na média do valor de módulo de elasticidade. Entretanto, nos dois percentuais de adição de CCA o percentual de medidas com valores entre $15 \mathrm{GPa}$ e $35 \mathrm{GPa}$ se elevou, o que 
indica que a adição de CCA gerou maior quantidade de compostos dessa natureza no exemplar, contribuindo para suas propriedades mecânicas.

Essa metodologia não demonstrou variação nos resultados de elasticidade entre as faixas com diferentes espessuras, corroborando as conclusões obtidas no método 2 , de não haver diferenças de módulo entre a zona de transição e a argamassa nos exemplares ensaiados.

Uma segunda análise, considerando os valores abaixo de $15 \mathrm{GPa}$ (Figura 12) - típicos de regiões com maior porosidade -, também indica que não há grandes alterações nas regiões analisadas com a utilização de FB em comparação com a referência, tanto pela média de valores quanto pelo percentual. Já as argamassas que utilizaram CCA apresentaram valores médios de módulo de elasticidade que superam a referência. As argamassas com CCA também apresentam pequena quantidade de valores de indentação com módulo inferior a $15 \mathrm{GPa}$, o que justifica a melhoria de resistência ocorrida em função da adição da CCA.
A determinação do módulo de elasticidade ao longo das diferentes espessuras de análise confirma o observado nas demais metodologias, não exibindo diferenças entre as menores e as maiores extensões de leitura para uma mesma interface.

\section{Comentários finais}

As propriedades macroestruturais comprovaram a influência das adições nas argamassas moldadas, com destaque para o maior desempenho das argamassas com CCA. O mapeamento dos valores de módulo de elasticidade dinâmico determinados por nanoindentação comprova que a utilização de CCA altera a região de interface em comparação com uma argamassa sem adição e com as que fizeram uso de FB, tornando-a mais rígida, com maior quantidade de compostos com valores de módulo de elasticidade compatível com C-S-H e com menor quantidade de poros e vazios.

Figura 11 - Valores médios e incidência de módulo de elasticidade entre 15 GPa e 35 GPa - método 3
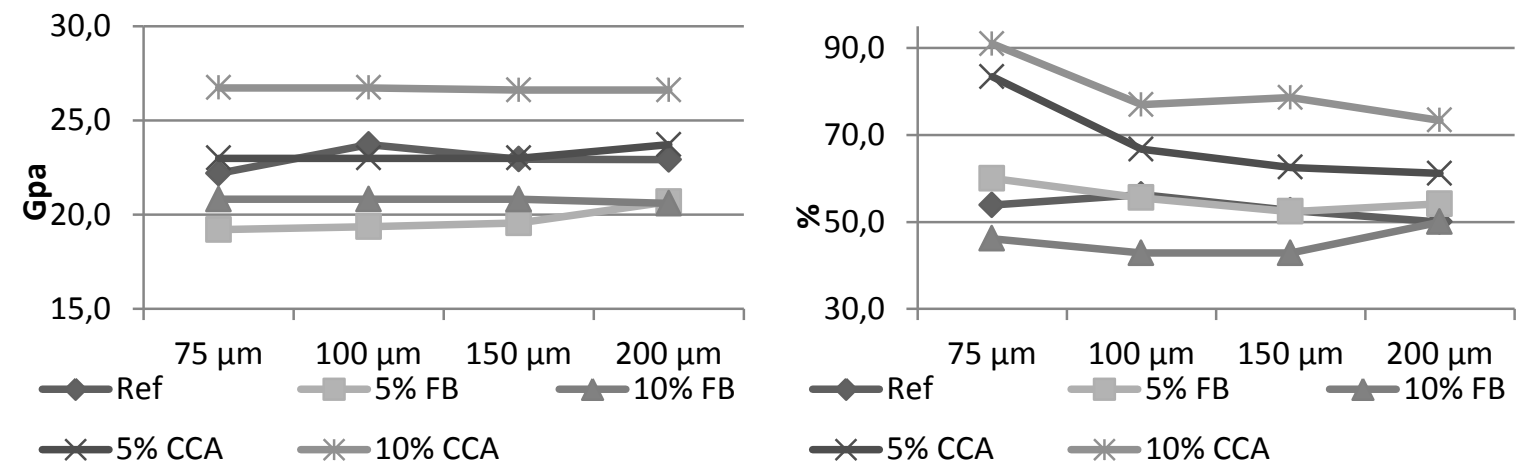

Figura 12 - Valores médios e incidência de módulo de elasticidade abaixo de 15 GPa - Método 3
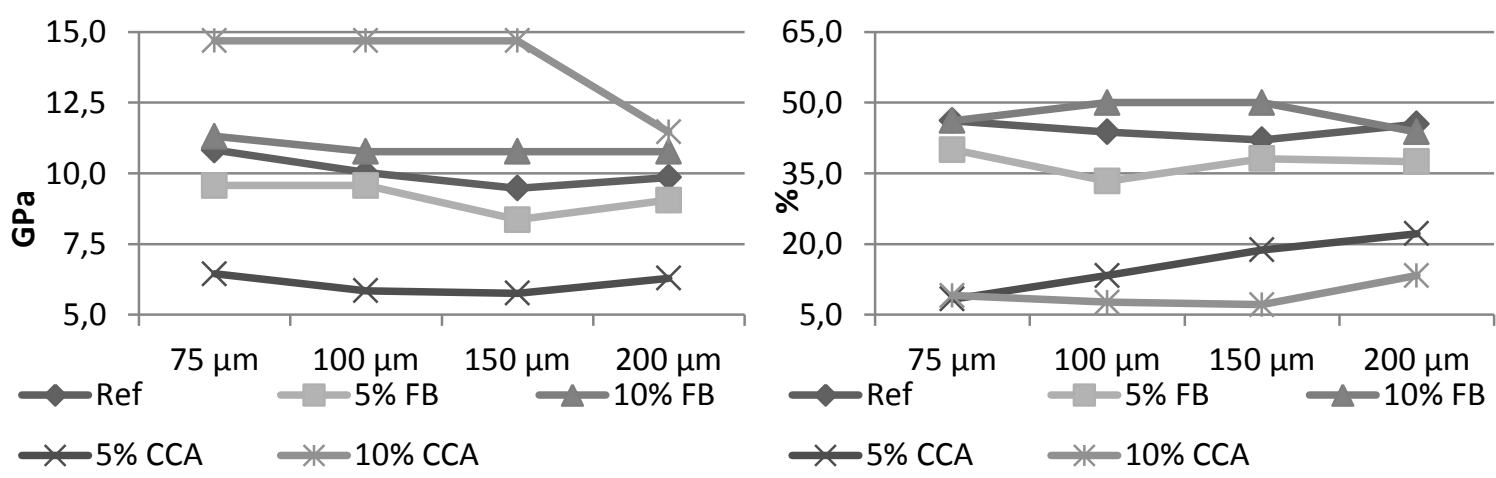

264 Wilbert, D. G. B.; Kazmierczak, C. de S.; Kulakowski, M. P. 
Em todas as interfaces estudadas não se identificaram regiões com menor módulo de elasticidade em comparação com as regiões mais distantes, características de zona de transição em concretos com agregados naturais, o que indica que a adição de agregados reciclados secos durante a execução da mistura do concreto gera interfaces de elevada qualidade, minimizando a ocorrência de maior porosidade, típica da zona de transição em concretos com agregados convencionais. Esse comportamento pode ser explicado pela condição de umidade do ARC, que estava seco no momento da aplicação da argamassa nova. Nesse estado de umidade, juntamente com a elevada fluidez da argamassa nova $(\mathrm{a} / \mathrm{c}=0,62)$, ocorreu migração de água e de finas partículas dos aglomerantes para o agregado reciclado, resultando numa zona de transição com módulo de elasticidade similar ao da matriz.

O uso simultâneo dos três métodos de análise propostos permitiu a identificação de alterações nas regiões de interface entre os diferentes traços utilizados e justifica a melhoria nas propriedades mecânicas proporcionada pela adição de CCA.

\section{Referências}

AGRELA, F. et al. Limiting Properties in the Characterisation of Mixed Recycled Aggregates for Use in the Manufacture of Concrete.

Construction and Building Materials, v. 25, n. 10, p. 3950-3955, 2011.

ÂNGULO, S. C. et al. On the Classification of Mixed Construction and Demolition Waste Aggregate by Porosity and Its Impact on the Mechanical Performance of Concrete. Materials and Structures, v. 43, n. 4, p. 519-528, 2010.

\section{ÂNGULO, S. C. Variabilidade de Agregados Graúdos de Construção e Demolição de reciclados. São Paulo, 2000. 155 f. Dissertação (Mestrado em Engenharia Civil) - Escola Politécnica, Departamento de Engenharia de Construção Civil, Universidade de São Paulo, São Paulo, 2000.}

\section{ASSOCIAÇÃO BRASILEIRA DE NORMAS} TÉCNICAS. NBR 12653: materiais pozolânicos: requisitos. Rio de Janeiro, 2014.

\section{ASSOCIAÇÃO BRASILEIRA DE NORMAS TÉCNICAS. NBR 7215: cimento Portland:} determinação da resistência à compressão. Rio de Janeiro, 1996.

\section{ASSOCIAÇÃO BRASILEIRA DE NORMAS} TÉCNICAS. NBR 8802: concreto endurecido: determinação da velocidade de propagação de onda ultrassônica. Rio de Janeiro, 2013.
ASSOCIAÇÃO BRASILEIRA DE NORMAS TÉCNICAS. NBR NM 248: agregados: determinação da composição granulométrica. Rio de Janeiro, 2003.

\section{ASSOCIAÇÃO BRASILEIRA DE NORMAS}

TÉCNICAS. NBR NM 45: agregados:

determinação da densidade de massa e do volume de vazios. Rio de Janeiro, 2006.

\section{ASSOCIAÇÃO BRASILEIRA DE NORMAS TÉCNICAS. NBR NM 46: agregados:} determinação do material fino que passa através da peneira $75 \mu \mathrm{m}$, por lavagem. Rio de Janeiro, 2003.

\section{ASSOCIAÇÃO BRASILEIRA DE NORMAS} TÉCNICAS. NBR NM 52: agregado miúdo: determinação da massa específica e massa específica aparente. Rio de Janeiro, 2003.

\section{ASSOCIAÇÃO BRASILEIRA DE NORMAS} TÉCNICAS. NBR NM 53: teor de material fino que passa através da peneira $75 \mu \mathrm{m}$ por lavagem. Rio de Janeiro, 2002.

BASHEER, L.; BASHEER, P. A. M.; LONG, A. E. Influence of Coarse Aggregate on the Permeation, Durability and the Microstructure Characteristics of Ordinary Portland Cement Concrete. Construction and Building Materials, v. 19, p. 682-690, 2005.

BENTZ, D. P. Influence of Internal Curing Using Lightweight Aggregates on Interfacial Transition Zone Percolation and Chloride Ingress in Mortars. Cement \& Concrete Composites, v. 31, p. 285 289, 2009.

BLANDO, E. Estudo, Desenvolvimento e Caracterização de Revestimentos do Tipo Super-Rede de Dureza. Porto Alegre, 2005. 137 f. Tese (Doutorado em Engenharia Metalúrgica e de Materiais) - Programa de Pós-Graduação em Engenharia de Minas, Metalúrgica e de Materiais, Universidade Federal do Rio Grande do Sul, Porto Alegre, 2005.

\section{BUTTLER, A. M. Concreto Com Agregados}

Graúdos Reciclados de Concreto: influência da idade de reciclagem nas propriedades dos agregados e concretos reciclados. São Carlos, 2003. 187 f. Dissertação (Mestrado em Engenharia Civil) - Escola de Engenharia de São Carlos, Departamento de Engenharia de Estruturas, Universidade de São Paulo, São Carlos, 2003.

CONSTANTINIDES, G.; ULM, F. J. The Effect of Two Types of C-S-H on the Elasticity of Cement-Based Materials: results from nanoindentation and micromechanical modeling. Cement and Concrete Research, v. 34, p. 67-80, 2004. 
CONSTANTINIDES, G.; ULM, F. J. The Nanogranular Nature of C-S-H. Journal of the Mechanics and Physics of Solids, v. 55, p. 64-90, 2007.

DIAMOND, S.; HUANG, J. The ITZ in Concrete: a different view based on image analysis and SEM observations. Cement \& Concrete Composites, v. 23, p. 179-188, 2001.

ELSHARIEF, A.; COHEN, M. D.; OLEK, J. Influence of Aggregate Size, Water Cement Ratio and Age on the Microstructure of the Interfacial Transition Zone. Cement and Concrete Research, v. 33, n. 11, p. 1837-1849, 2003.

ERHART, R. L. Influência do Chapisco Com Cinza de Casca de Arroz na Aderência de Argamassa em Substratos Cerâmicos Com Diferentes Porosidades. São Leopoldo, 2014. 205 f. Dissertação (Mestrado em Engenharia Civil) Programa de Pós-Graduação em Engenharia Civil, Universidade do Vale do Rio dos Sinos, São Leopoldo, 2014.

ETXEBERRIA, M. et al. Influence of Amount of Recycled Coarse Aggregates and Production Process on Properties of Recycled Aggregate Concrete. Cement and Concrete Research, v. 37, n. 5, p. 735-742, 2007.

ETXEBERRIA, M.; VÁZQUEZ, E.; MARÍ, A. Microstructure Analysis of Hardened Recycled Aggregate Concrete. Magazine of Concrete Research, v. 58, n. 10, p. 683-690, 2006.

EVANGELISTA, L.; BRITO, J. DE. Mechanical Behavior of Concrete Made With fine Recycled Concrete Aggregates. Cement and Concrete Composites, v. 29, n. 5, p. 397-401, 2007.

FEDUMENTI, M. B. Avaliação da Influência da Cinza da Casca de Arroz no Comportamento de Concretos Com Agregado Reciclado de Concreto em Relação a Propriedades Mecânicas e de Durabilidade, Com Ênfase no Transporte de Íons Cloretos. São Leopoldo, 2013. 134 f. Dissertação (Mestrado em Engenharia Civil) - Programa de Pós-Graduação em Engenharia Civil, Universidade do Vale do Rio dos Sinos, São Leopoldo, 2013.

HU, C.; LI, Z. Property Investigation of Individual Phases in Cementitious Composites Containing Silica Fume and Fly ash. Cement \& Concrete Composites, v. 57, p. 17-26, mar. 2015.

JENNINGS, H. M. et al. A Multi-Technique Investigation of the Nanoporosity of Cement Paste. Cement and Concrete Research, v. 37, p. 329336, 2007.
JOHN, V. M. Reciclagem de Resíduos na Construção Civil: contribuição à metodologia de pesquisa e desenvolvimento. São Paulo, 2000. 102 f. Tese (Livre Docência) - Escola Politécnica, Universidade de São Paulo, São Paulo, 2000.

JONES, C. A.; GRASLEY, Z. C. Short-Term Creep of Cement Paste During Nanoindentation. Cement \& Concrete Composites, v. 33, n. 1, p. 12-18, 2011.

KATZ, A. Properties of Concrete Made With Recycled Aggregate From Partially Hydrated old Concrete. Cement and Concrete Research, v. 33, n. 5, p. 703-711, 2003.

KE, Y. et al. Identification of Microstructural Characteristics in Lightweight Aggregates Concrete by Micromechanical Modelling Including the Interfational Transition Zone. Cement and Concrete Research, v. 40, n. 11, p. 1590-1600, 2010.

KONG, D. et al. Effect and Mechanism of Surface-Coating Pozzalanics Materials Around Aggregate on Properties and ITZ Microstructure of Recycled Aggregate Concrete. Construction and Building Materials, v. 24, n. 5, p. 701-708, 2010.

KOU, S.; POON, C. Effect of the Quality of Parent Concrete on the Properties of High Performance Recycled Aggregate Concrete. Construction and Building Materials, v. 77, p. 501-508, 2015.

KOU, S. C.; POON, C. S. Enhancing the Durability Properties of Concrete Prepared With Coarse Recycled Aggregate. Construction and Building Materials, v. 35, p. 69-76, 2012.

LIMA, J. A. R. Proposição de Diretrizes Para Produção e Normalização de Resíduo de Construção Reciclado e de Suas Aplicações em Argamassas e Concretos. São CARLOS, 1999. 240 f. Dissertação (Mestrado em Arquitetura e Urbanismo) - Escola de Engenharia de São Carlos, Universidade de São Paulo, São Carlos, 1999.

LOVATO, P. S. Verificação dos Parâmetros de Controle de Agregados Reciclados de Resíduos de Construção e Demolição Para Utilização em Concreto. Porto Alegre, 2007. 180 f. Dissertação (Mestrado em Engenharia Civil) - Programa de Pós-Graduação em Engenharia Civil, Universidade Federal do Rio Grande do Sul, Porto Alegre, 2007.

MEHTA, P. K.; MONTEIRO, P. J. M. Concreto: microestrutura, propriedades e materiais. 3. ed. São Paulo: Ibracon, 2008.

NEVILLE, A. M.; BROOKS, J. J. Propriedades do Concreto. 2. ed. São Paulo: Pini, 2013. 
PADMINI, A. K.; RAMAMURTHY, K.;

MATHEWS, M. S. Influence of parent concrete on the properties of recycled aggregate concrete.

Construction and Building Materials, v. 23, n. 2, p. 829-836, 2009.

PADOVAN, R. G. Influência da Pré-Molhagem nas Propriedades de Concretos Produzidos Com Agregados Reciclados de Concreto. São Leopoldo, 2013. 154 f. Dissertação (Mestrado em Engenharia Civil) - Programa de Pós-Graduação em Engenharia Civil, Universidade do Vale do Rio dos Sinos, São Leopoldo, 2013.

PAULON, V.; KIRCHHEIM, A. P. Nanoestrutura e Microestrutura do Concreto Endurecido. In: ISAIA, G. C. (Org.). Concreto: ciência e tecnologia. São Paulo: Ibracon, 2011.

PINTO, T. P. Metodologia Para a Gestão Diferenciada de Resíduos Sólidos da Construção Urbana. São Paulo, 1999. 189 f. Tese (Doutorado em Engenharia Civil) - Escola Politécnica, Universidade de São Paulo, São Paulo, 1999.

POON, C.; SHUI, Z.; LAM, L. Effect of Microstructure of ITZ on Compressive Strength of Concrete Prepared With Recycled Aggregates. Construction and Building Materials, v. 18, n. 6 , p. 461-468, 2004.

SILVA, W. R. L.; NĚMEČEK, J.; ŠTEMBERK, P. Methodology for Nanoindentation-Assisted Prediction of Macroscale Elastic Properties of High Performance Cementitious Composites. Cement \& Concrete Composites, v. 45, p. 57-68, 2014.

SICAT, E. et al. Experimental Investigation of the Deformational Behavior of the Interfacial Transition Zone (ITZ) in Concrete During Freezing and Thawing Cycles. Construction and Building Materials, v. 65, p. 122-131, 2014.

SIDOROVA, A. et al. Study of the Recycled Aggregates Nature's Influence on the AggregateCement Paste Interface and ITZ. Construction and Building Materials, v. 68, p. 677-684, 2014.

SORELLI, L. et al. The Nano-Mechanical Signature of Ultra High Performance Concrete by Statistical Nanoindentation Techniques. Cement and Concrete Research, v. 38, n. 12, p. 14471456, 2008.

TAM, V. W. Y.; GAO, X. F.; TAM, C. M. Microstructural Analysis of Recycled Aggregate Concrete Produced From Two-Stage Mixing Approach. Cement and Concrete Research, v. 35, n. 6, p. 1195-1203, 2005.
TEGGUER, A. D. Determining the Water Absorption of Recycled Aggregates Utilizing Hydrostatic Weighing Approach. Construction and Building Materials, v. 27, n. 1, p. 112-116, 2012.

THOMAS, C. et al. Durability of Recycled Aggregate Concrete. Construction and Building Materials, v. 40, p. 1054-1065, 2013.

TOPÇU, İ. B.; ŞENGEL, S. Properties of Concretes Produced With Waste Concrete Aggregate. Cement and Concrete Research, v. 34, n. 8, p. 1307-1312, 2004.

ULM, F. J. et al. Does Microstructure Matter for Statistical Nanoindentation Techniques? Cement \& Concrete Composites, v. 32, n. 4, p. 92-99, 2010.

VENKOVIC, N.; SORELLI, L.; MARTIRENA, F. Nanoindentation Study of Calcium Silicate Hydrates in Concrete Produced With Effective Microorganisms-Based Bioplasticizer. Cement \& Concrete Composites, v. 49, p. 127-139, 2014.

VIEIRA, G. L. Estudo do Processo de Corrosão Sob a Ação de Íons Cloretos em Concretos Obtidos a Partir de Agregados Reciclados de Resíduos de Construção e Demolição. Porto Alegre, 2003. 150 f. Dissertação (Mestrado em Engenharia Civil) - Programa de Pós-Graduação em Engenharia Civil, Universidade Federal do Rio Grande do Sul, Porto Alegre, 2003.

WANG, X. H. et al. Aplication of Nanoindentation Testing to Study of the Interfacial Transition Zone in Steel Fiber Reinforced Mortar. Cement and Concrete Research, v. 39, n. 8, p. 701-715, 2009.

WERLE, A. P.; KAZMIERCZAK, C. S.; KULAKOWSKI, M. P. Carbonatação em Concretos Com Agregados Reciclados de Concreto. Ambiente Construído, Porto Alegre, v. 11, n. 2, p. 213-228, abr./jun. 2011.

XIAO, J. et al. Effects of Interfacial Transition Zones on the Stress-Strain Behavior of Modeled Recycled Aggregate Concrete. Cement and Concrete Research, v. 52, p. 82-99, 2013.

ZAHARIEVA, R. et al. Assessment of the Surface Permeation Properties of Recycled Aggregate Concrete. Cement and Concrete Composites, v. 25, n. 2, p. 223-232, 2003.

ZHU, W. et al. Nanoindentation Mapping of Mechanical Properties of Cement Paste and Natural Rocks. Materials Characterization, v. 58, p. 1189-1198, 2007. 
ZORDAN, S. E. A Utilização de Entulho Como Agregado, na Confecção do Concreto.

Campinas, 1997. 156 f. Dissertação (Mestrado em Engenharia Civil) - Faculdade de Engenharia

Civil, Universidade Estadual de Campinas, Campinas, 1997.

\section{Agradecimentos}

Os autores agradecem ao Gepsi/TecnoPUCRS pelo auxílio na realização dos ensaios de nanoindentação, à Fapergs pela bolsa de Mestrado concedida ao primeiro autor, e à Finep pelo fomento à pesquisa.

Daniel Gustavo Brusius Wilbert

Programa de Pós-Graduação em Engenharia Civil, Unidade Acadêmica de Pesquisa e Pós-Graduação | Universidade do Vale do Rio dos Sinos | Av. Unisinos, 950, Cristo Rei | Caixa Postal 275 | São Leopoldo - RS - Brasil | CEP 93022-000 | Tel.: (51) 3591-1264 |

E-mail: danielwilbert@brturbo.com.br

\section{Claudio de Souza Kazmierczak}

Programa de Pós-Graduação em Engenharia Civil, Unidade Acadêmica de Pesquisa e Pós-Graduação | Universidade do Vale do Rio dos Sinos | Tel.: (51) 3590-8245 | E-mail: claudiok@unisinos.br

\section{Marlova Piva Kulakowski}

Programa de Pós-Graduação em Engenharia Civil, Unidade Acadêmica de Pesquisa e Pós-Graduação | Universidade do Vale do Rio dos Sinos | Tel.: (51) 3591-1264 | E-mail: marlovak@unisinos.br

\section{Revista Ambiente Construído}

Associação Nacional de Tecnologia do Ambiente Construído

Av. Osvaldo Aranha, $99-3^{\circ}$ andar, Centro

Porto Alegre - RS - Brasil

CEP $90035-190$

Telefone: +55 (51) 3308-4084

Fax: +55 (51) 3308-4054

www.seer.ufrgs.br/ambienteconstruido

E-mail: ambienteconstruido@ufrgs.br 